\title{
Fabrication and Optimization of Proton Conductive Polybenzimidazole Electrospun Nanofiber Membranes
}

\author{
Sassan Jahangiri a,b, İpek Aravia, Lale Işıkel Şanlı c, Yusuf Z. Menceloğlu ${ }^{\text {c,d }}$, Elif \\ Özden-Yenigün ${ }^{\mathrm{a}, \mathrm{b}^{*}}$ \\ ${ }^{a}$ Department of Textile Engineering, Istanbul Technical University, Istanbul Turkey \\ ${ }^{\mathrm{b}}$ ITU Aerospace Research Center, Istanbul Technical University, Istanbul, Turkey \\ c SUNUM Research Center, Sabanci University, Istanbul, Turkey \\ ${ }^{\mathrm{d}}$ Department of Material Science and Engineering, Sabanci University, Istanbul Turkey \\ *Correspondence: ozdenyenigun@itu.edu.tr
}

\begin{abstract}
Phosphoric acid (PA)-doped polybenzimidazole (PBI) proton exchange membranes (PEM) have received attention due to their good mechanical properties, moderate gas permeability and superior proton conductivity under high temperature operation. Among PBI based film membranes, nanofibrous membranes withstand to higher strain due to strongly oriented polymer chains while exhibiting higher specific surface area with increased number of proton conducting sites. In this study, PBI electrospun nanofibers were produced and doped with PA to operate as high temperature PEM, while changes in proton conductivity and morphologies were monitored. Proton conductive PBI nanofiber membranes by using the process parameters of $15 \mathrm{kV}$ and $100 \mu \mathrm{l} / \mathrm{hr}$, at $15 \mathrm{wt} \% \mathrm{PBI} /$ dimethylacetamide (DMAc) polymer concentration were prepared by varying PA doping time as 24, 48, 72 and 96 hours (hr). The morphological changes associated with PA doping addressed that acid doping significantly caused swelling and 2-fold increase in mean fiber diameter. Tensile strength of the membranes is found to be increased by doping level, whereas the strain at break (15\%) decreased due to the brittle nature of $H$-bond network. $72 \mathrm{hr}$ doped PBI membranes demonstrated highest proton conductivity whereas the decrease on conductivity for 96hr doped PBI membranes which could be attributed to the morphological changes due to $H$-bond network and acid leaking, were noted. Overall, the results suggested that of $72 \mathrm{hr}$ doped PBI membranes with
\end{abstract}


proton conductivity of $123 \mathrm{mS} / \mathrm{cm}$, could be a potential candidate for proton exchange membrane fuel cell (PEMFC).

Keywords: Polybenzimidazole; nanofiber; proton conductivity; fuel cell; high temperature proton exchange membrane

\section{Introduction}

Poly[2,2'-(m-phenylene)-5,5'-bibenzimidazole], polybenzimidazole (PBI) developed in early 1960s, exhibits excellent mechanical, chemical and thermal properties ${ }^{[1]}$. PBI membranes attract a great deal of attention as means for increasing the temperature tolerance of conventional proton exchange membranes (PEM) materials. PBI (Grotthuss (hopping) conduction mechanism of phosphoric acid doped-polybenzimidazole PA-PBI is depicted in Figure 1) is capable of absorbing acids ( $\mathrm{pKa} \sim 5.5$ ), which is essential to be used in fuel cell membranes and other proton-conducting applications ${ }^{[2]}$. To overcome the drawbacks of the low-temperature proton exchange membrane fuel cell (PEMFC) such as CO catalyst poisoning, necessity of humidification, heat management, and low diffusion rates of protons, PBI based membranes were preferred due to their superior proton conductivity particularly both at high temperatures ${ }^{[3-5]}$ and at $0 \%$ relative humidity ${ }^{[6]}$. PA-PBI membranes were first successfully prepared by Wainright et al. ${ }^{[7-9]}$. These membranes were recommended as electrolyte for high temperature proton exchange membrane fuel cell (HTPEMFC) operating at temperatures of up to $200^{\circ} \mathrm{C}{ }^{[8]}$. They also exhibited good mechanical properties, and low gas permeability ${ }^{[10-12]}$ compared to water containing membranes including Nafion ${ }^{\circledR}$ whose proton conductivity decreases with increased temperature due to the evaporation of $\mathrm{H}_{2} 0$ molecules ${ }^{[13]}$. In addition, the results showed that an increase in doping level resulted in better proton conductivity, and so more efficient HT-PEMFC performance ${ }^{[8,14]}$. After blended with PA, PBI films might suffer from deterioration due to the slow elution of water-soluble PA, when the vapor was produced ${ }^{[15]}$. Moreover, it was reported that these film membranes also sacrificed the 
mechanical properties after PA doping. Other macroscopic forms of PBI such as nanofibers ${ }^{[16]}$, PBI fiber incorporated films ${ }^{[17,18]}$ and reinforced films ${ }^{[19-23]}$ could overcome these challenges while improving mechanical properties. Among nanofiber production methods, electrospinning approach has received wide attention due to its simple implementation. Randomly oriented electrospun nanofibers benefiting from highly oriented chains along fiber axis have much better tearing and tensile strength than casted films ${ }^{[24-26]}$. The production of PBI nanofibers via electrospinning was first studied by Kim et.al. ${ }^{[16]}$ and it is pointed out that sulfonic acid treatment increased the mechanical properties of these nanofibers. Dong et al. ${ }^{[27]}$ fabricated high purity Nafion® electrospun nanofibers and reported one order of magnitude higher proton conductivity compared to bulk Nafion films. This increase was associated to the alignment of the ionic aggregates along fiber axis and also augmented by decreasing fibers diameter. Later, Yu et. al. ${ }^{[28]}$ produced PBI electrospun mats and immersed them into $\mathrm{Nafion}^{\circledR}$ to produce composite membranes for HTPEMFC. The effect of temperature on PA-PBI membrane conductivity was investigated by Lobato et al., and they reported that dramatically increased proton conductivity with temperature due to promoted proton transportation ${ }^{[29]}$. Recently, Lai et al. prepared ultra-thin cross-linked PBI membranes by electron beam irradiation method and noted that these cross-linked membranes had better mechanical performance than pristine PBI membranes as expected ${ }^{[30]}$.

Recent efforts have focused on the preparation of membranes using constructed ion-conductive nanofibrous networks rather than films ${ }^{[31,32]}$. These nanofibers have a very high specific surface to volume ratio, better mechanical performance than films and good pore interconnectivity, which are highly demanding properties in PEMFC. Hwang et al. ${ }^{[33]}$ reported moderate proton conductivity of PA-PBI based nanofiber membranes as $0.081 \mathrm{~S} / \mathrm{cm}$ and higher water uptake around 40\%, whereas commercial Nafion ${ }^{\circledR}$ exhibited $0.09 \mathrm{~S} / \mathrm{cm}$. Later, Kawakami et al. fabricated PA doped 
sulfonated polyimide (SPI)/PBI composites and investigated ultra-fast proton conduction mechanism which was presumably derived from the aggregation of sulfonic acid groups and acid base interactions at the nanofiber surface ${ }^{[34]}$. To date, many studies have been focused on creating

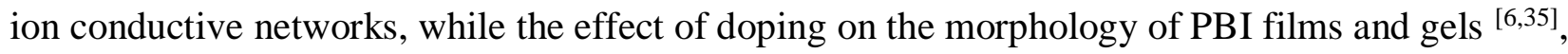
mechanical and thermal properties were revealed. However, nanofibrous PBI membranes exhibited higher degree of crystallinity and higher porosity with surface roughness compared to casted membranes. All these structural parameters have influence on proton conduction mechanism which strongly depends on the distribution of accumulated doped acid molecules and acid uptake, thus the role of nanofiber morphology should be explored in detail.

In this study, we present the structural design of PEMs with PBI nanofiber membranes at different PA doping levels. Our present experimental procedure began with exploring the effect of electrospinning parameters such as feeding rate, applied voltage and polymer concentration on neat PBI fiber morphology. Hence, a factorial design of experiments (DOE) was performed to determine optimal set of parameters for effective electrospun fibrous membranes. The PBI nanofibers as determined by this DOE were characterized primarily to achieve reproducible PBI nanofiber mats and then PA doped nanofiber membranes were obtained by soaking into PA solution by varying doping time as 24 hour (hr), 48hr, 72hr and 96hr. The morphologies of undoped and doped PBI membranes were systemically evaluated by scanning electron microscope (SEM). To explore the doping mechanism and effective doping time, Fourier transform infrared spectroscopy (FT-IR) was used. The mechanical response and thermal stability were also investigated both for undoped PBI and PA doped proton conductive PBI membranes. The proton conductivity of these membranes were studied at room temperature under hydrous conditions to reveal the dominant effect of $\mathrm{H}$ bonding nanofibrous network on the prevention of acid leaking. 


\section{Materials and Methods}

PBI S26 Solution with viscosity of $2100 \pm 200$ poise at $25^{\circ} \mathrm{C}$ (containing $26.2 \mathrm{wt} \%$ of PBI powder with repeating unit MW of $308 \mathrm{~g} / \mathrm{mole}, 18000$ chain weight average MW and inherent viscosity of $0.46 \mathrm{dL} / \mathrm{g}, 72.3 \mathrm{wt} \% \mathrm{~N}, \mathrm{~N}$-dimethylacetamide (DMAc) and $1.5 \mathrm{wt} \% \mathrm{LiCl}$ ), was purchased from PBI Products Inc. USA. Solvent DMAc, PA and deionized water (DI) were supplied by Sigma Aldrich Chemical Co. All chemicals are used without further purification. Electrospinning solutions were prepared at three different PBI concentrations $10 \mathrm{wt} \%, 12.5 \mathrm{wt} \%$ and $15 \mathrm{wt} \%$ by diluting PBI condensed solutions. Each PBI/DMAc solutions was stirred magnetically for $24 \mathrm{hr}$ at room temperature, to ensure homogeneity. With three levels of each variable, the polymer concentration, applied voltage and feeding rate, a total of fifteen different combinations were used to produce nanofiber (Table 1). An electrical bias potential was applied to the polymer solutions in electrospinning device $\left(\operatorname{Argeteknolab}^{\circledR}\right)$ which were contained in a $5 \mathrm{~mL}$ syringe. An alligator clip attached to the syringe needle (inner diameter $300 \mu \mathrm{m}$ ) enabled biasing of the solution. The applied voltage was adjusted, while the grounded rounding drum covered with aluminum foil was placed $10 \mathrm{~cm}$ away from the syringe needle tip. A syringe pump (NewEra NE 1000 Syringe Pump) was used to maintain a solution flow rate during electrospinning. The experiments for electrospun PBI nanofiber processing are summarized in Table 1. In order to gain proton conductivity, PBI electrospun nanofibers were doped with 85\% PA at room temperature for 24, 48, 72 and $96 \mathrm{hr}$ consecutively. Then, doped PBI mats were washed with distilled water at least five times, dried in vacuum oven at $150{ }^{\circ} \mathrm{C}$ for $2 \mathrm{hr}$ to ensure the removal of existing $\mathrm{LiCl}$ and conditioned prior testing [36]. 
For characterizing the materials and processes in this work, a variety of techniques and equipment were used. The morphologies of doped and undoped fibrous webs were evaluated by imaging using $2 \mathrm{keV}$ secondary electrons in field-emission gun equipped scanning electron microscope (FE-SEM, LEO 1530VP). The diameter of electrospun nanofibers was estimated by ImageJ software ${ }^{\circledR}$. The average fiber diameter and distribution were determined from at least 40 measurements on the randomly selected fibers. Thermogravimetric analysis (TGA) were carried out on Netzsch-STA equipment to probe the degradation temperature of mats, as a measure of the thermal stability of membranes under the conditions of $\mathrm{N}_{2}$ atmosphere, heating rate of $5 \mathrm{~K} / \mathrm{min}$, with $75 \mathrm{~mL} / \mathrm{min}$ gas flow from room temperature to $1200{ }^{\circ} \mathrm{C}$. To verify the effect of PA in the composite nanofiber mats, FT-IR spectroscopy (Perkin Elmer UATR Two) was used to see structural response which was in the range of 4000-400 $\mathrm{cm}^{-1}$. Universal Testing Machine (UTM) (Shimadzu AG-X Plus 100kN) was used to determine tensile strength and tensile modulus using the standard ASTM D882-12. The dimensions of testing samples were $60 \times 20 \mathrm{~mm}$ and the thickness of mats were $30 \mu \mathrm{m}$. The extension rate was calculated as in equation (1):

$$
V=0.1 * L
$$

where $V$ is the extension rate $(\mathrm{mm} / \mathrm{min})$ and $L$ is the length of the specimen.

To measure the proton conductivity of the doped PBI membranes Bekktech in-plane conductivity method was used. For this aim, the specimens were cut into $2 \times 2 \mathrm{~cm}$ membrane pieces, placed into the conductivity cell and immersed into the DI water bath. The 4-point proton conductivity method was conducted at the standard room temperature and $100 \%$ relative humidity $(\mathrm{RH})$. The proton conductivity and specific resistance of the membranes were calculated from the resultant resistance using the equation (2) as: 


$$
\sigma=\left(\frac{T}{R * A}\right)
$$

where $\sigma$ is the conductivity in $\mathrm{S} / \mathrm{cm}, R$ is the resistance offered by the membrane in ohms, $T$ is the thickness of the membrane in $\mathrm{cm}, A$ is the area of the membrane in $\mathrm{cm}^{2}$.

\section{Results and Discussion}

Properties of the electrospun nanofibers, in particular the fiber diameter and morphology, depend on various parameters that can be divided into three groups: polymer solution properties (solution viscosity, solution concentration, polymer molecular weight etc.); processing conditions (applied voltage, volume flow rate etc.); and ambient conditions (temperature, humidity etc. ${ }^{[37]}$ ). In this study, ambient conditions were held constant, in order to systematically investigate the effects of processing and solution properties on the mean fiber diameter and bead formation. First, three levels of polymer concentration $(10 \mathrm{wt} \%, 12.5 \mathrm{wt} \%$ and $15 \mathrm{wt} \%)$ and three levels of feeding rate $(70,85$ and $100 \mu \mathrm{L} / \mathrm{hr}$ ) resulted in nine possible combinations for factor setting at constant $15 \mathrm{kV}$ (Table 1). Then the feeding rate was kept constant and the effects of applied voltage and polymer concentration on mean fiber diameter was discovered, in tandem.

First, electrospun mats were produced by varying polymer concentration such as $10 \mathrm{wt} \%, 12.5 \mathrm{wt} \%$ and $15 \mathrm{wt} \%$ at $15 \mathrm{kV}$ constant DC voltage while the feeding rates were differed from 70 to 100 $\mu 1 /$ hr as shown in Table 1. Figure 2 (Figure S1 gives fiber diameter distribution of each mat) shows the SEM micrographs of fibers obtained by varying the polymer concentration and feeding rate at $15 \mathrm{kV}$ and a constant nozzle-collector distance of $10 \mathrm{~cm}$. Using a polymer concentration of $10 \mathrm{wt} \%$ yielded thinner fibers (50\% narrower compared to nanofibers at $15 \mathrm{wt} \%$ ), but less homogeneous nanowebs due to bead formations. Besides, in PBI-1 systems, we could not obtain stable flow for 
electrospinning. To increase flow rate from $70 \mu \mathrm{L} / \mathrm{hr}$ to $85 \mu \mathrm{L} / \mathrm{hr}$ and $100 \mu \mathrm{L} / \mathrm{hr}$ enabled fiber formation but it could not prevent partial electrospraying and electrosprayed beads. Thus, we raised polymer concentration to $12.5 \mathrm{wt} \%$. However, the process again resulted in spraying along with spinning, which again prevented the formation of homogenous webs at $12.5 \mathrm{wt} \%$ concentrations. It is worthy to note that increasing feeding rate at this concentration also led to the formation of beadlike structures and thicker fibers with high variance in fiber diameter. It was known that increasing the feeding rate decreased the charge density, whereas intense charge density lead to jet bending instabilities, that caused the formation of thinner fibers ${ }^{[38,39]}$. Besides, when the feeding rate is higher, solvent molecules cannot be fully evaporated and that resulted in bead-like formation ${ }^{[40,41]}$. Figure 2 suggests that homogenous webs for PEM can be obtained at polymer concentration of 15 wt $\%$. PBI-9 systems exhibited bead-free mats with mean fiber diameter of $170 \pm 10 \mathrm{~nm}$ whereas PBI-7 and PBI-8 systems have mean fiber diameter of $179 \pm 11 \mathrm{~nm}$ and $184 \pm 13 \mathrm{~nm}$, respectively. PBI-9 system was chosen due to their narrower fiber diameter distribution and bead-free mat morphologies for further studies. Afterwards, $100 \mu \mathrm{L} / \mathrm{hr}$ feeding rate was kept constant to shed a light on the effects of polymer concentration and applied voltage on the fiber morphology $(12,15$ and $18 \mathrm{kV}$ and 10, 12.5 and $15 \mathrm{wt} \%)$. It was still not possible to achieve homogenous webs at lower concentrations (10 wt\% and 12.5\%). Besides, applied voltage has impact on bead formation in which is more obvious at $12.5 \mathrm{wt} \%$ polymer concentrations. As seen in Figure 3 (Figure S2 provides fiber diameter distribution of each mat), PBI-15 (mean fiber diameter $173 \pm 8 \mathrm{~nm}$ ) system resulted in reproducible nanofiber webs with thicker fibers compared to PBI-9 and PBI-14 (mean fiber diameter $121 \pm 6 \mathrm{~nm}$ ) systems. High electrostatic forces as $18 \mathrm{kV}$ caused wider fiber diameter distribution. Overall, PBI-9 system have promised reproducible homogenous nanofiber webs, thus 
these process parameters were chosen for the production of PBI mats for proton conducting membranes.

PBI electrospun nanofibers were doped with $85 \mathrm{wt} \%$ PA at room temperature for 24, 48, 72 and 96 hr.

First, FT-IR analysis was conducted to examine the protonation degree of PA in PBI polymer structure by monitoring doping time. PA doping in PBI resulted in broad absorption bands at between 2400 and $3000 \mathrm{~cm}^{-1}$, which were sensitive to the protonation of $N$-sites on the imidazole groups of PBI, and thus was not observed in undoped PBI membranes ${ }^{[42]}$. This absorption band increases with the degree of protonation ${ }^{[42]}$ where the absorption band of acid anion $\left(\mathrm{H}_{2} \mathrm{PO}_{4}^{-}\right)$ between 400 and $1300 \mathrm{~cm}^{-1}$ represents the protonation degree of PBI, as displayed in Figure 4. In addition, the area under the peaks at $1565 \mathrm{~cm}^{-1}$ and $1630 \mathrm{~cm}^{-1}$ are sensitive to the acid content in the membrane ${ }^{[43]}$. The area under the peak at $1630 \mathrm{~cm}^{-1}$ increases with the doping level and it reaches a maximum value which corresponds to transfer of two protons (from PA to the two imidazole groups) of the repeating unit PBI ${ }^{[43]}$. The presence of the absorption band at $942 \mathrm{~cm}^{-1}$ is also attributed to the presence of $\mathrm{H}_{2} \mathrm{PO}_{4}{ }^{-}$ions. The absorption band at $998 \mathrm{~cm}^{-1}$ keeps growing when the amount of acid in membrane exceeds the number of imidazole sites and free PA accumulates in the membrane ${ }^{[42]}$. IR analysis of PA doped PBI membranes revealed that there is excessive amount of PA molecules accumulated, as interpreted from the absorption peak at 998 $\mathrm{cm}^{-1}$, and it increased with doping time. To reveal the effect of free acid molecules and acid doping on fiber morphologies, we performed SEM analysis, which will be discussed in next section.

The conductivity measurements would provide complimentary information to optimize required doping time. Table 2 displays the proton conductivity measurements of PA doped PBI nanofiber membranes at room temperature and 100\% RH. Undoped PBI membranes are not proton 
conducting materials but, a PA molecule can be immobilized via protonating a benzimidazole ring, when it is accumulated in PBI membranes, as depicted in Figure ${ }^{[44]}{ }^{[4}$ It also enables proton conductivity at higher temperatures up to $200^{\circ} \mathrm{C}$ without any requirement of any diffusion ease media such as water. But herein, we preferred to test in hydrous medium to see the effectiveness of nanofibrous network on the prevention of acid leaking. Proton conductivity strongly depends on the amount of acid present in the membrane. So, the conductivities of PBI nanofiber membranes after immersion into PA bath for $24 \mathrm{hr}, 48 \mathrm{hr}, 72 \mathrm{hr}$ and $96 \mathrm{hr}$ time intervals at room temperature are reported in Table 2. The results suggested that PA immersion for $72 \mathrm{hr}$ leads to highest proton conductivity. Even though, the time of immersion in the acid bath is an important factor for proton conductivity, we observed that best conductivity value, cannot be achieved for the samples immersed during $96 \mathrm{hr}$. This can be attributed to the morphological changes due to the formed $\mathrm{H}$ bonding network ${ }^{[45,46]}$ and free PA molecules accumulated into the membrane which caused acid leaking ${ }^{[47,48]}$. Thus, we studied the morphological changes depending on immersion time by SEM, as given in Figure 5.

The mean fiber diameters of undoped and 24hr, 48hr, 72hr and 96hr doped PBI membranes were $170 \pm 10,574 \pm 55,915 \pm 74,327 \pm 23$ and $418 \pm 37 \mathrm{~nm}$ respectively. Investigation on the mean fiber diameter showed that $72 \mathrm{hr}$ doped PBI fibers have minimum fiber diameter deviation and more homogenous fibers. As displayed in Figure 5 (Figure S3 provides fiber diameter distribution of each mat), acid immersion caused significant changes in fiber morphology which could be related to the swelling effect of physisorbed PA molecules and coalesced neighboring fibers due to $H$-bond network. In these membranes, free acid can be easily eluted by washing ${ }^{[49]}$. On one hand, FTIR analysis pointed out that there were excess acid molecules in the membrane that increases proton conductivity. On the other hand, the decrease in proton conductivity for $96 \mathrm{hr}$ doped PBI membranes 
was observed related to acid leaking in membrane due to over saturation (Table 2). These merged and swelled fibers (as seen in Figure 5d) may augment the effect of PA dehydration. As reported by Litt et al. PA separation from the more crystalline PBI phase, produces more concentrated acid domains ${ }^{[48]}$. This phenomenon might cause uneven distribution of PA molecules and changes in resistivity. As a consequence, 96hr PA doped PBI membranes exhibited higher resistivity than $72 \mathrm{hr}$ PA doped PBI membranes ${ }^{[48]}$. Among the well-known factors directly affecting conductivity such as nature of the acid, temperature, relative humidity, we noted that for fibrous membranes fiber morphology has influence on proton conduction mechanism due to the variations of accumulated PA molecules.

Thermogravimetric analysis was conducted to find the decomposition temperature of undoped and PA doped PBI nanofibers. As seen in Figure 6a, decomposition temperature of optimized undoped PBI nanofibers were at around $700^{\circ} \mathrm{C}$ whereas first mass change interpreted from DTG $(\% / \mathrm{min})$ took place at around $80^{\circ} \mathrm{C}$ due to the decomposed $\mathrm{LiCl}$ stabilizer ${ }^{[36]}$. To remove the inevitable entrapped DMAc solvent molecules and $\mathrm{LiCl}$ stabilizer, prior proton conductivity measurements, each membrane were dried in vacuum oven at $150^{\circ} \mathrm{C}$ for $2 \mathrm{hr}$ and conditioned. The effect of doping time on decomposition temperature was studied at time intervals of $24 \mathrm{hr}, 48 \mathrm{hr}, 72 \mathrm{hr}$ and $96 \mathrm{hr}$ (see Figure 6b-e). Figure 6b suggests that PA doping for $24 \mathrm{hr}$ altered decomposition temperature to $820^{\circ} \mathrm{C}$ due to formed $\mathrm{H}$-bond network where PA doping for $48 \mathrm{hr}$ shifted this temperature to $840^{\circ} \mathrm{C}$ (Figure 6c). Besides, another peak was observed at the range of $160-200^{\circ} \mathrm{C}$ in Figure 6c, which pointed out the excess amount of PA molecules. Figure 6d revealed that PA doping during $72 \mathrm{hr}$ increased decomposition temperature to $860^{\circ} \mathrm{C}$. However, when the doping time was altered to 96hr, two more distinctive peaks (at around $650^{\circ} \mathrm{C}$ and $800^{\circ} \mathrm{C}$ ) were observed as displayed in Figure 6e. Broader peak at around $650-700^{\circ} \mathrm{C}$ pointed out the undoped PBI structures which can 
be seen due to the accumulation of PA molecules. This uneven distribution of PA molecules caused decreased in proton conductivity, was also noted in the morphological changes.

Mechanical properties of undoped and PA doped PBI membranes were investigated so that an associated reinforcement due to the doping could be evaluated. Hydrogen bonding between $N$ and - $\mathrm{NH}$ - groups in PBI, are the dominant molecular forces, resulting in close chain packing, so as good mechanical performance of these membranes ${ }^{[9,50,51]}$. However, the results showed that PA doping sacrificed mechanical properties of PBI films ${ }^{[15]}$, so several approaches including crosslinked ${ }^{[52]}$ and reinforced membranes ${ }^{[21,23]}$ were investigated to improve tensile properties. Figure 7 and Table 3, emphasized on the effect of doping time, and reported the Young's modulus, ultimate strength and elongation at break (\%) of the doped and undoped membranes. The results suggested that due to $H$-bond network, ultimate tensile strength increased by doping time while plastic deformation was observed in all cases. At the same time, these inter-molecular forces contributed to brittleness of membranes due to formed restrictions on plasticization. Thus, PA doped membranes showed lower ductility than neat specimens. Table 3 pointed out that $96 \mathrm{hr}$ PA doped PBI electrospun membranes had lower ultimate tensile strength and Young's modulus than $72 \mathrm{hr}$ PA doped PBI electrospun membranes. This decrease in Young's modulus and ultimate tensile strength could be related to differences in accumulation of PA molecules which caused doped and undoped sites. Thus, even though the synergetic effect of interconnected network increased stiffness and strength, undoped regions promoted lower stiffness and strength. Previous studies reported that in high doping levels due to the separation of inter-chains, mechanical properties were decreased contrary to the effect of crosslinking or interconnected network ${ }^{[53,54]}$.

Table 3 also exhibits the dimensional changes (\%) and mass change (\%) upon acid doping for undoped and 24hr, 48hr, $72 \mathrm{hr}$ and $96 \mathrm{hr}$ doped PBI-9 mats with $30 \mu \mathrm{m}$ thickness. Results suggest 
that PA rich domains in the membrane resulted in higher proton conductivity due to the interaction of water and excess acid molecules in hydrous medium. At the same time, these PA concentrated domains caused to adsorb more water molecules ${ }^{[45]}$. We immersed commercial PBI film, undoped PBI and doped PBI nanofibrous membranes into dye colored DI water bath to visually monitor the water diffusion and then to calculate water uptake (\%), as given in Figure S4. It is clear that compared to PBI proton exchange film, much more water molecules were accumulated into the nanofibrous PBI membranes, thus revealing higher difference in water uptake (\%). When PBI membrane was doped, the active sites of the imidazole ring were preferably occupied by the acid molecules, thus the water uptake becomes consequently lower, as seen in Figure S4. Once the system reached saturation at higher acid doping levels, the water uptake was also influenced by the excess of hygroscopic acid and so water uptake (\%) slightly increased as the doping level rises, as in $72 \mathrm{hr}$ and $96 \mathrm{hr}$ doped PBI-9 membranes. The swelling related to PA doping also could be interpreted from the mass change \% as predicted. Randomness of nanofibers do not create any anisotropic behavior in the membranes. When the membranes were doped, depending on the distribution of PA molecules and new formed short-range linkages, physical properties may differ and exhibit directionality. Each doped specimen showed contraction (\%) both in $x$ and $z$ direction. We should note that along $x$-direction, due to the use of rotating drum during electrospinning, nanofibers were slightly better oriented compared to $z$-direction. Hence, oriented chains preferably in $x$-directions showed lower contraction value (\%) as seen in Table 3. Moreover, local undoped and doped sites in 96hr doped PBI-9 membranes can lead to higher contraction (\%) in $z$ axis than in $x$-axis, finally caused anisotropy in doped membrane.

\section{Conclusion}


Produced PBI electrospun nanofiber mats were optimized systematically, based on the fiber diameter and morphology of fibers, and among 15 different systems, the best results were obtained at PBI-9 system with mean fiber diameter of $170 \pm 10 \mathrm{~nm}$. Immersion in PA for $72 \mathrm{hr}$ leaded to highest proton conductivity whereas the conductivity of $96 \mathrm{hr}$ doped PBI mats was decreased. On the other hand, PA doping significantly caused swelling and 2-fold increase in mean fiber diameter and leaded to anisotropy in fibrous membranes. FT-IR analysis demonstrated that the amount of accumulated PA increased by doping time but still there was excessive PA molecules seen. So, the results revealed that the morphological changes due to $H$-bond network and free PA molecules accumulated into the membrane caused acid leaking. Thermogravimetric analysis also pointed out the two degradation peaks around $650^{\circ} \mathrm{C}$ and $800^{\circ} \mathrm{C}$ for $96 \mathrm{hr}$ PA doped membranes due to uneven distribution of PA molecules which induced doped and undoped regions. Tensile strength of the membranes was found to be increased by doping level, whereas the strain at break (\%) decreased due to the brittle nature of formed network.

\section{Supporting information is available.}

\section{Acknowledgement}

This study is funded by TUBITAK (The Scientific and Technological Research Council of Turkey) (Grant Number: 114M149), under R\&D Projects funding program.

\section{References}

1. Vogel H, Marvel CS. Polybenzimidazoles, new thermally stable polymers. J Polym Sci, Part A: Polym Chem. 1961, 50(154), 511-539.

2. Dawkins BG, Qin F, Gruender M, Copeland GS. High temperature polymer blends. United Kingdom: Woodhead Publishing; 2014. 
3. Mamlouk M, Ocon P, Scott K. Preparation and characterization of polybenzimidzaole/diethylamine hydrogen sulphate for medium temperature proton exchange membrane fuel cells. J Power Sources. 2014, 245, 915-926.

4. Marsh G. Membranes fit for a revolution. Mater Today. 2003, 6(3), 38-43.

5. Li S, Liu M. Synthesis and conductivity of proton-electrolyte membranes based on hybrid inorganic-organic copolymers. Electrochim Acta. 2003, 48(28), 4271-4276.

6. Sannigrahi A, Ghosh S, Maity S, Jana T. Polybenzimidazole gel membrane for the use in fuel cell. Polymer. 2011, 52(19), 4319-4330.

7. Wang S, Zhao C, Ma W, et al. Preparation and properties of epoxy-cross-linked porous polybenzimidazole for high temperature proton exchange membrane fuel cells. J Membr Sci. 2012, 411-412, 54-63.

8. Wainright JS WJ, Weng D, Savinell RF and Litt M. Acid-Doped Polybenzimidazoles: A New Polymer Electrolyte. J Electrochem Soc. 1955, 142(7), 121-123.

9. Wang JT, Savinell RF, Wainright J, Litt M, Yu H. A H2O2 fuel cell using acid doped polybenzimidazole as polymer electrolyte. Electrochim Acta. 1996, 41(2), 193-197.

10. He RH, Li QF, Jensen JO, Bjerrum NJ. Doping phosphoric acid in polybenzimidazole membranes for high temperature proton exchange membrane fuel cells. J Polym Sci Pol Chem. 2007, 45(14), 2989-2997.

11. Xiao L, Zhang H, Jana T, et al. Synthesis and Characterization of Pyridine-Based Polybenzimidazoles for High Temperature Polymer Electrolyte Membrane Fuel Cell Applications. Fuel Cells. 2005, 5(2), 287-295.

12. Weber J, Kreuer KD, Maier J, Thomas A. Proton Conductivity Enhancement by Nanostructural Control of Poly(benzimidazole)-Phosphoric Acid Adducts. Adv Mater. 2008, 2595-2598.

13. Sumner JJ, Creager SE, Ma JJ, DesMarteau DD. Proton Conductivity in Nafion ${ }^{\circledR} 117$ and in a Novel Bis[(perfluoroalkyl)sulfonyl]imide Ionomer Membrane. J Electrochem Soc. 1998, 145(1), 107-110.

14. Bin Du QG, Zhigang Qi, Leng Mao, Richard Pollard and John F. Elter. Materials for proton exchange membrane fuel cells. Florida, USA: CRC Press; 2007.

15. Guan YS, Pu HT, Jin M, Chang ZH, Wan DC. Preparation and Characterisation of Proton Exchange Membranes Based on Crosslinked Polybenzimidazole and Phosphoric Acid. Fuel Cells. 2010, 10(6), 973-982.

16. Kim J-S, Reneker DH. Polybenzimidazole nanofiber produced by electrospinning. Polym Eng Sci. 1999, 39(5), 849-854.

17. Li H-Y, Liu Y-L. Polyelectrolyte composite membranes of polybenzimidazole and crosslinked polybenzimidazole-polybenzoxazine electrospun nanofibers for proton exchange membrane fuel cells. J Mater Chem A. 2013, 1(4), 1171-1178.

18. Yu T-LL. Nafion/PBI Nanofiber Composite Membranes for Fuel Cells Applications. ASME 2010 8th International Fuel Cell Science, Engineering and Technology Conference. 2010, 2.

19. Ghosh S, Sannigrahi A, Maity S, Jana T. Role of Clays Structures on the Polybenzimidazole Nanocomposites: Potential Membranes for the Use in Polymer Electrolyte Membrane Fuel Cell. J Phys Chem C. 2011, 115(23), 11474-11483.

20. Maity S, Singha S, Jana T. Low acid leaching PEM for fuel cell based on polybenzimidazole nanocomposites with protic ionic liquid modified silica. Polymer. 2015, 66, 76-85. 
21. Pu H, Liu L, Chang Z, Yuan J. Organic/inorganic composite membranes based on polybenzimidazole and nano-SiO2. Electrochim Acta. 2009, 54(28), 7536-7541.

22. Singha S, Jana T. Structure and Properties of Polybenzimidazole/Silica Nanocomposite Electrolyte Membrane: Influence of Organic/Inorganic Interface. Acs Appl Mater Inter. 2014, 6(23), 21286-21296.

23. Staiti P. Proton conductive membranes based on silicotungstic acid/silica and polybenzimidazole. Materials Letters. 2001, 47(4-5), 241-246.

24. Bazbouz MB, Stylios GK. The tensile properties of electrospun nylon 6 single nanofibers. Journal of Polymer Science Part B: Polymer Physics. 2010, 48(15), 1719-1731.

25. Jiang S. Electrospun Nanofiber Reinforced Composites: Fabrication and Properties [Doctoral thesis]: Faculty of Biology, University of Bayreuth; 2014.

26. Yao J, Bastiaansen C, Peijs T. High Strength and High Modulus Electrospun Nanofibers. Fibers. 2014, 2(2), 158.

27. Dong B, Gwee L, Salas-de la Cruz D, Winey KI, Elabd YA. Super proton conductive high-purity nafion nanofibers. Nano Lett. 2010, 10(9), 3785-3790.

28. Yu T-LL, Liu S-H, Lin H-L, Su P-H. Nafion/PBI Nanofiber Composite Membranes for Fuel Cells Applications. ASME 2010 8th International Fuel Cell Science, Engineering and Technology Conference. 2010, (44052), 631-639.

29. Lobato J, Cañizares P, Rodrigo MA, Linares JJ. PBI-based polymer electrolyte membranes fuel cells: Temperature effects on cell performance and catalyst stability. Electrochim Acta. 2007, 52(12), 3910-3920.

30. Lai S, Park J, Cho S, Tsai M, Lim H, Chen K. Mechanical property enhancement of ultrathin PBI membrane by electron beam irradiation for PEM fuel cell. Int J Hydrogen Energ. 2016, 41(22), 9556-9562.

31. Li H-Y, Liu Y-L. Nafion-functionalized electrospun poly(vinylidene fluoride) (PVDF) nanofibers for high performance proton exchange membranes in fuel cells. J Mater Chem A. 2014, 2(11), 3783-3793.

32. Xu X, Li L, Wang H, Li X, Zhuang X. Solution blown sulfonated poly(ether ether ketone) nanofiber-Nafion composite membranes for proton exchange membrane fuel cells. Rsc Adv. 2015, 5(7), 4934-4940.

33. Hwang K, Kim J-H, Kim S-Y, Byun H. Preparation of Polybenzimidazole-Based Membranes and Their Potential Applications in the Fuel Cell System. Energies. 2014, 7(3), 1721.

34. Tanaka M. Development of ion conductive nanofibers for polymer electrolyte fuel cells. Polym J. 2016, 48(1), 51-58.

35. Sannigrahi A, Arunbabu D, Jana T. Thermoreversible gelation of polybenzimidazole in phosphoric acid. Macromol Rapid Comm. 2006, 27(22), 1962-1967.

36. PBI Performance Products. Polybenzimidazole (PBI) S26 Solution. https://pbipolymer.com/wp-content/uploads/2016/05/Celazole-PBI-S26-TypicalProperties.pdf. Accessed 15.05.2017.

37. Ozden-Yenigun E, Menceloglu YZ, Papila M. MWCNTs/P(St-co-GMA) Composite Nanofibers of Engineered Interface Chemistry for Epoxy Matrix Nanocomposites. Acs Appl Mater Inter. 2012, 4(2), 777-784.

38. Mitchell SB, Sanders JE. A unique device for controlled electrospinning. J Biomed Mater Res A. 2006, 78(1), 110-120. 
39. Son WK, Youk JH, Lee TS, Park WH. The effects of solution properties and polyelectrolyte on electrospinning of ultrafine poly(ethylene oxide) fibers. Polym J. 2004, 45(9), 2959-2966.

40. Yuan X, Zhang Y, Dong C, Sheng J. Morphology of ultrafine polysulfone fibers prepared by electrospinning. Polym Int. 2004, 53(11), 1704-1710.

41. Zuo W, Zhu M, Yang W, Yu H, Chen Y, Zhang Y. Experimental study on relationship between jet instability and formation of beaded fibers during electrospinning. Polym Eng Sci. 2005, 45(5), 704-709.

42. Zeis R. Materials and characterization techniques for

high-temperature polymer electrolyte membrane fuel cells. J Nanotechnol. 2015, 6(feul cell membrane), 68-83.

43. Bouchet R, Siebert E. Proton conduction in acid doped polybenzimidazole. Solid State Ionics. 1999, 118(3-4), 287-299.

44. Asensio JA, Sanchez EM, Gomez-Romero P. Proton-conducting membranes based on benzimidazole polymers for high-temperature PEM fuel cells. A chemical quest. Chem Soc Rev. 2010, 39(8), 3210-3239.

45. Ma YL, Wainright JS, Litt MH, Savinell RF. Conductivity of PBI membranes for hightemperature polymer electrolyte fuel cells. J Electrochem Soc. 2004, 151(1), A8-A16.

46. Mader J, Xiao L, Schmidt TJ, Benicewicz BC. Polybenzimidazole/Acid Complexes as High-Temperature Membranes. In: Scherer GG, ed. Fuel Cells II. Springer Berlin Heidelberg. 2008:63-124.

47. Oono Y, Sounai A, Hori M. Influence of the phosphoric acid-doping level in a polybenzimidazole membrane on the cell performance of high-temperature proton exchange membrane fuel cells. J Power Sources. 2009, 189(2), 943-949.

48. Litt M, Ameri R, Wang Y, Savinell R, Wainwright J. Polybenzimidazoles/Phosphoric Acid Solid Polymer Electrolytes: Mechanical and Electrical Properties. MRS Proceedings. 2011, 548.

49. Li Q, He R, Berg RW, Hjuler HA, Bjerrum NJ. Water uptake and acid doping of polybenzimidazoles as electrolyte membranes for fuel cells. Solid State Ionics. 2004, 168(1-2), 177-185.

50. Aili D, Cleemann LN, Li Q, Jensen JO, Christensen E, Bjerrum NJ. Thermal curing of PBI membranes for high temperature PEM fuel cells. J Mater Chem. 2012, 22(12), 54445453.

51. Li Q, Jensen JO, Savinell RF, Bjerrum NJ. High temperature proton exchange membranes based on polybenzimidazoles for fuel cells. Prog Polym Sci. 2009, 34(5), 449-477.

52. Noyé P, Li Q, Pan C, Bjerrum NJ. Cross-linked polybenzimidazole membranes for high temperature proton exchange membrane fuel cells with dichloromethyl phosphinic acid as a cross-linker. Polym Advan Technol. 2008, 19(9), 1270-1275.

53. Park J, Wang L, Advani SG, Prasad AK. Mechanical Stability of H3PO4-Doped PBI/Hydrophilic-Pretreated PTFE Membranes for High Temperature PEMFCs. Electrochim Acta. 2014, 120, 30-38.

54. Bose S, Kuila T, Nguyen TXH, Kim NH, Lau K-t, Lee JH. Polymer membranes for high temperature proton exchange membrane fuel cell: Recent advances and challenges. Prog Polym Sci. 2011, 36(6), 813-843. 
Table 1. Electrospun PBI nanofibers and their assigned electrospinning parameters

\begin{tabular}{|c|c|c|c|}
\hline $\begin{array}{l}\text { Specimen } \\
\text { Name }\end{array}$ & $\begin{array}{c}\text { Polymer } \\
\text { concentration } \\
(w t \%)\end{array}$ & $\begin{array}{c}\text { Applied Voltage } \\
(\mathbf{k V})\end{array}$ & $\begin{array}{c}\text { Feeding Rate } \\
(\mu \mathrm{L} / \mathrm{hr})\end{array}$ \\
\hline PBI-1 & 10 & 15 & 70 \\
\hline PBI-2 & 10 & 15 & 85 \\
\hline PBI-3 & 10 & 15 & 100 \\
\hline PBI-4 & 12.5 & 15 & 70 \\
\hline PBI-5 & 12.5 & 15 & 85 \\
\hline PBI-6 & 12.5 & 15 & 100 \\
\hline PBI-7 & 15 & 15 & 70 \\
\hline PBI-8 & 15 & 15 & 85 \\
\hline PBI-9 & 15 & 15 & 100 \\
\hline PBI-10 & 10 & 12 & 100 \\
\hline $\mathrm{PBI}-11$ & 10 & 18 & 100 \\
\hline PBI-12 & 12.5 & 12 & 100 \\
\hline $\mathrm{PBI}-13$ & 12.5 & 18 & 100 \\
\hline PBI-14 & 15 & 12 & 100 \\
\hline PBI-15 & 15 & 18 & 100 \\
\hline
\end{tabular}


Table 2. Proton conductivity and resistivity of produced doped PBI-9 membranes in $100 \%$ $\mathrm{RH}$ at room temperature.

\begin{tabular}{cccc}
\hline Membrane & $\begin{array}{c}\text { Resistance } \\
\text { (Ohms) }\end{array}$ & $\begin{array}{c}\text { Resistivity } \\
(\text { ohm. cm })\end{array}$ & $\begin{array}{c}\text { Conductivity } \\
(\mathbf{m S} / \mathbf{c m})\end{array}$ \\
\hline PBI-9-24 hr & 2.14 & 14.445 & 69 \\
\hline PBI-9-48 hr & 1.4 & 9.45 & 106 \\
\hline PBI-9-72 hr & 1.2 & 8.1 & 123 \\
\hline PBI-9-96 hr & 1.4 & 9.45 & 106 \\
\hline
\end{tabular}


Table 3. Dimensional changes (\%) and mass change (\%)upon acid doping for undoped and 24hr, 48hr, 72hr and 96hr doped PBI-9 membranes with $30 \mu \mathrm{m}$ thickness are reported. Tensile properties such as Young's modulus, strain at break (\%) and ultimate strength are given for all doped and undoped membranes. ( $x$ and $z$ stand for the length and width of membranes, respectively)

\begin{tabular}{|c|c|c|c|c|c|c|}
\hline \multirow[b]{2}{*}{ Membrane } & \multirow[b]{2}{*}{$\begin{array}{c}\text { Young`s } \\
\text { modulus } \\
(\mathrm{MPa})\end{array}$} & \multirow[b]{2}{*}{$\begin{array}{c}\text { Ultimate } \\
\text { strength } \\
\text { (MPa) }\end{array}$} & \multirow[b]{2}{*}{$\begin{array}{c}\text { Strain at } \\
\text { break }(\%)\end{array}$} & \multirow[b]{2}{*}{$\begin{array}{l}\text { Mass change } \\
\text { after doping }\end{array}$} & \multicolumn{2}{|c|}{$\begin{array}{c}\text { Dimensional } \\
\text { changes upon } \\
\text { acid doping } \\
(\%)\end{array}$} \\
\hline & & & & & $\chi$ & $\mathbf{Z}$ \\
\hline $\begin{array}{l}\text { Undoped } \\
\text { PBI-9 }\end{array}$ & $0.65 \pm 0.05$ & $4.19 \pm 0.65$ & $24.0 \pm 4.8$ & & & \\
\hline PBI-9-24 hr & $0.39 \pm 0.01$ & $4.40 \pm 1.28$ & $23.95 \pm 6.68$ & $26.3 \pm 4.6$ & -21.2 & -25 \\
\hline PBI-9-48 hr & $0.32 \pm 0.29$ & $3.80 \pm 0.08$ & $25.19 \pm 15.23$ & $21.1 \pm 0.7$ & -20 & -25 \\
\hline PBI-9-72 hr & $2.55 \pm 0.44$ & $10.24 \pm 1.98$ & $15.03 \pm 0.154$ & $27.3 \pm 3.2$ & -21.8 & -25 \\
\hline PBI-9-96 hr & $1.08 \pm 0.08$ & $15.00 \pm 1.41$ & $10.51 \pm 14.49$ & $26.4 \pm 2.7$ & -15.6 & -25 \\
\hline
\end{tabular}

